\title{
PENGEMBANGAN MEDIA PEMBELAJARAN INTERAKTIF BERBASIS AUTOPLAY PADA MATERI GERBANG LOGIKA UNTUK SISWA KELAS X TAV DI SMK NEGERI 3 SINGARAJA
}

\author{
K. Candra Kuniartha ${ }^{1}$, I P. Suka Arsa², G. Ratnaya ${ }^{3}$ \\ 1,2,3Prodi Pendidikan Teknik Elektro, Universitas Pendidikan Ganesha,Singaraja \\ e-mail: candraoutsider83@gmail.com, suka.arsa@undiksha.ac.id, gede.ratnaya@undiksha.ac.id
}

\begin{abstract}
Abstrak
Penelitian ini bertujuan untuk membuat media pembelajaran interaktif berbasis autoplay yang dapat digunakan untuk membantu proses pembelajaran, mengetahui tingkat kelayakan media pembelajaran dan respon siswa setelah menggunakan media pembelajaran interaktif berbasis autoplay. Penelitian ini merupakan jenis Research and Development (R \& D) dan penelitian ini menggunakan kuesioner sebagai instrument pengumpulan data oleh ahli isi (ahli materi), ahli media dan siswa. Penelitian ini dilakukan pada siswa kelas X TAV 1 di SMK Negeri 3 Singaraja. Hasil penelitian terhadap media didapatkan: 1) persentase tingkat kelayakan media dari validator media $90 \%$ dengan kualifikasi sangat layak, 2) persentase tingkat kelayakan media dari validator materi $90 \%$ dengan dengan kualifikasi sangat layak, 3) hasil uji coba dalam kelompok kecil mendapatkan persentase $87 \%$ dengan kualifikasi sangat layak, 4) hasil uji coba kelompok besar mendapatkan persentase $91,37 \%$ dengan kualifikasi sangat layak. Berdasarkan hasil analisis tingkat kelayakan dan respon siswa, media pembelajaran interaktif berbasis autoplay pada materi gerbang logika untuk kelas X TAV di SMK N 3 Singaraja layak digunakan sebagai media pembelajaran.
\end{abstract}

Kata kunci: Media pembelajaran, Autoplay, Gerbang Logika

This research aims to made autoplay based interactive learning media which can be used to support teaching and learning process, to know the feasibility level of learning media and students respond after using this autoplay based interactive learning media. This study was research and development study $(R \& D)$ the data of this study were collected using questionnaire as an instruments by a content expert (material expert), expert of media and students. This study was conducted at tenth grade (X) TAV student of SMK Negeri 3 Singaraja. The results showed that: 1) the percentage of the media feasibility level from media validator is $90 \%$ with very feasible qualifications, 2) the percentage of the media feasibility level from material validator is $90 \%$ with very feasible qualifications, 3) test result of small group the percentage is $87 \%$ with very feasible qualifications 4) test result of large group the percentage is $91,37 \%$. Based on the result of the analysis the feasibility level and students respond autoplay based interactive learning media on logic gate material for tenth grade $(X)$ TAV student of SMK Negeri 3 Singaraja proper to use as learning media.

Keywords: Learning media, autoplay, logic gate

\section{Pendahuluan}

Pendidikan pada era globalisasi ini merupakan kebutuhan yang sangat dibutuhkan untuk masa depan seseorang. Tanpa melalui proses pendidikan yang baik, sulit kiranya seseorang untuk menyesuaikan diri dengan perkembangan zaman saat ini. Pendidikan merupakan suatu proses pengalaman. Karena kehidupan merupakan pertumbuhan, maka pendidikan berarti membantu pertumbuhan batin manusia tanpa dibatasi oleh usia. Proses pertumbuhan adalah proses penyesuaian pada setiap fase dan menambah kecakapan dalam perkembangan seseorang melalui pendidikan. Pendidikan adalah proses pemartabatan manusia menuju puncak optimasi potensi kognitif, afektif, dan psikomotorik yang dimilikinya. Pendidikan merupakan suatu kebutuhan yang harus dipenuhi dalam kehidupan bermasyarakat, berbangsa, dan bernegara serta membantu mereka membuat keputusan yang dapat dipertanggungjawabkan. Peran pendidikan sangatlah penting, sebab pendidikan adalah pembelajaran pengetahuan, keterampilan, dan kebiasaan sekelompok orang yang diturunkan 
dari satu generasi ke generasi berikutnya melalui pengajaran, pelatihan, atau penelitian. Pendidikan sering terjadi di bawah bimbingan orang lain, tetapi juga memungkinkan secara otodidak.

Sesuai dengan amanat Peraturan Pemerintah Nomor 32 tahun 2013 tentang Standar Nasional Pendidikan, salah satu standar yang harus dikembangkan adalah proses. Standar proses adalah standar nasional yang berkaitan dengan pelaksanaan kegiatan pembelajaran pada satuan pendidikan untuk mencapai kompetensi lulusan. Standar proses berisi kriteria minimal proses pembelajaran pada satuan pendidikan dasar dan menengah di seluruh Indonesia. Standar proses meliputi perencanaan proses pembelajaran, pelaksanaan proses pembelajaran, penilaian hasil pembelajaran dan pengawasan proses pembelajaran yang efektif dan efisien.

Sekolah Menengah Kejuruan (SMK) merupakan salah satu lembaga pendidikan kejuruan yang mempunyai tugas untuk mempersiapkan peserta didiknya setelah lulus agar dapat bekerja langsung sesuai bidang-bidang tertentu sesuai jurusan yang dipilih. Saputra (2015:63) menyatakan dalam proses pembelajarannya, SMK dilengkapi dengan ilmu teori dan juga peserta didik dibekali melalui praktek sehingga dalam perkembangannya SMK harus mampu menciptakan lapangan pekerjaan dan sumber daya manusia (SDM) yang berkompeten dan dapat mengikuti kemajuan ilmu pengetahuan dan teknologi. SMK merupakan salah satu penyelenggara pendidikan yang mencetak tenaga kerja yang siap pakai sesuai kompetensi program keahlian mereka masing-masing.

Di SMK Negeri 3 Singaraja, siswanya dituntut untuk dapat menguasai semua ranah pendidikan, selain praktek teori juga dibutuhkan untuk membuktikan hasil praktikum atau membantu dalam proses jalannya praktikum. SMK Negeri 3 Singaraja memiliki 10 kompetensi keahlian, salah satunya adalah kompetensi keahlian Teknik Audio Video (TAV). Teknik Audio Video khususnya kelas X terdapat materi pelajaran Gerbang Logika yang merupakan mata pelajaran yang sangat penting untuk kelanjutan proses pembelajaran kejenjang yang lebih tinggi dan juga di dunia kerja pada saat ini.

Permasalahan yang dihadapi menurut hasil observasi dan juga melalui wawancara dengan guru mata pelajaran dasar listrik dan elektronika khususnya pada materi gerbang logika di SMK N 3 Singaraja adalah tidak keseluruhan siswa kelas X TAV memahami tentang materi gerbang logika, sehingga semangat siswa untuk belajar tentang gerbang logika tidak maksimal. Selain itu guru hanya menggunakan media berupa powerpoint dan hanya menggunakan model pembelajaran konvesional yang berupa ceramah. Siswa juga membutuhkan media pembelajaran yang bisa digunakan selain di sekolah, karena keterbatasan waktu yang dimiliki guru untuk memberikan pemahaman tentang materi gerbang logika. Sesuai dengan perkembangan teknologi sekarang, guru dapat menggunakan media pembelajaran interaktif untuk dapat memaksimalkan pembelajaran sehingga semangat siswa untuk belajar dapat meningkat.

SMK Negeri 3 Singaraja dipilih sebagai tempat penelitian karena selama ini di SMK Negeri 3 Singaraja khususnya kelas $X$ jurusan TAV belum ada media pembelajaran yang mendukung materi gerbang logika, jadi guru hanya memberikan petunjuk-petunjuk secara lisan dalam memberikan pemahaman tentang gerbang logika. Berdasarkan latar belakang yang telah dikemukakan, maka peneliti melakukan suatu penelitian tentang pengembangan media pembelajaran. Untuk pembelajaran peneliti ingin menggunakan media pembelajaran interaktif berbasis autopla untuk sarana pengembangan media belajar dan penghubung antara guru dengan siswa. Oleh karena itu diambil judul penelitian "Pengembangan Media Pembelajaran Interaktif Berbasis Autoplay Pada Materi Gerbang Logika Untuk Siswa Kelas X TAV di SMK N 3 Singaraja".

Dari latar belakang yang telah di tulis, peneliti memberikan identifikasi masalah yang akan di jadikan bahan penelitian sebagai berikut:(1) Tidak keseluruhan siswa kelas X TAV memahami tentang gerbang logika, sehingga semangat siswa untuk belajar gerbang logika tidak maksimal.(2) Guru hanya menggunakan media powerpoint dan model pembelajaran konvesional yang berupa ceramah.(3) Pembelajaran kurang maksimal karena kekurangan media pembelajaran interaktif.(4) Siswa membutuhkan media yang bisa digunakan selain di 
sekolah.(5) Keterbatasan waktu yang dimiliki guru untuk memberikan pemahaman tentang materi gerbang logika.

Berdasarkan identifikasi masalah yang disebutkan di atas, maka masalah yang akan dibatasi adalah guru hanya menggunakan media powerpoint dan model pembelajaran konvesional yang berupa ceramah, dan pembelajaran kurang maksimal karena kekurangan media pembelajaran interaktif.

Berdasarkan identifikasi masalah yang disebutkan di atas, maka rumusan masalah pada penelitian ini adalah sebagai berikut:(1) Bagaimanakah desain media pembelajaran interaktif berbasis autoplay pada materi gerbang logika untuk siswa kelas X TAV di SMK N 3 Singaraja?(2) Apakah media pembelajaran interaktif berbasis autoplay layak digunakan sebagai media pembelajaran pada materi gerbang logika untuk siswa kelas X TAV di SMK N 3 Singaraja?(3) Bagaimanakah respon siswa terhadap media pembelajaran interaktif berbasis autoplay pada materi gerbang logika untuk siswa kelas x TAV di SMK Negeri 3 Singaraja?.

Bertitik tolak dari perumusan masalah, maka tujuan penelitian ini yaitu:(1) Untuk membuat media pembelajaran interaktif berbasis autoplay pada materi gerbang logika untuk siswa kelas $x$ tav di SMK N 3 Singaraja.(2) Untuk mengetahui kelayakan media pembelajaran interaktif berbasis autoplay pada materi gerbang logika untuk siswa kelas $x$ tav di SMK N 3 Singaraja.(3) Untuk mengetahui respon siswa terhadap media pembelajaran interaktif berbasis autoplay pada materi gerbang logika untuk siswa kelas $x$ tav di SMK Negeri 3 Singaraja.

\section{Metode}

Dalam penelitian ini, peneliti menggunakan metode penelitian dan pengembangan atau lebih dikenal dengan Research and Development. Metode Penelitian dan Pengembangan adalah metode penelitian yang digunakan untuk menghasilkan produk tertentu dan menguji keefektifan produk tersebut Sugiyono (dalam Herlambang, 2018:32). Sedangkan menurut Borg dan Gall (dalam Arsa, 2017) penelitian pengembangan adalah penelitian yang berorientasi untuk mengembangkan dan validasi produk-produk dalam pendidikan. Berdasarkan teori tersebut, maka dapat disimpulkan bahwa penelitian ini termasuk Research and Development (R\&D) karena diterapkan pada materi gerbang logika yang berupa suatu media/produk untuk mengatasi permasalahan pembelajaran di kelas X TAV SMK Negeri 3 Singaraja.

Pada penelitian ini menggunakan model pengembangan menurut Sugiyono. Menurut Sugiyono (dalam Herlambang, 2018:32), ada 10 langkah-langkah dalam penelitian R\&D menurut Sugiyono antara lain: 1) Potensi dan masalah. 2) Pengumpulan data. 3) Desain produk. 4) Validasi desain. 5) Revisi desain. 6) Uji coba produk. 7) Revisi produk. 8) Uji coba pemakaian 9) Revisi produk. 10)Produksi masal.

Uji coba produk dilakukan untuk mengetahui dan mengumpulkan data yang didapat yang akan digunakan sebagai dasar untuk menetapkan tingkat keefektifan, efisiensi, atau kelayakan suatu produk yang dikembangkan atau yang dihasilkannya benar - benar berkualitas. Dalam penelitian ini teknik analisi data menggunakan statistik deskriptif persentase dan jenis data yang digunakan adalah data kuantitatif. Statistik deskriptif adalah statistik yang digunakan untuk menganalisis data dengan cara mendeskripsikan atau menggambarkan data yang terkumpul sebagaimana adanya tanpa bermaksud membuat kesimpulan yang berlaku untuk umum atau generalisasi (Sugiyono, 21015:207). 
Tabel 1. Kriteria Skor

\begin{tabular}{ccr}
\hline No & $\begin{array}{c}\text { Interva } \\
(\%)\end{array}$ & \multicolumn{1}{c}{ Kriteria } \\
\hline 1 & $84-100$ & Sangat layak \\
2 & $68-84$ & Layak \\
3 & $52-68$ & Cukup layak \\
4 & $36-52$ & Kurang layak \\
5 & $20-36$ & Sangat Tidak layak \\
\hline
\end{tabular}

Jika skor validasi yang diperoleh minimal 68,01 \% maka media pembelajaran yang dikembangkan tersebut layak dan dapat dimanfaatkan sebagai media pembelajaran dalam kegiatan belajar mengajar.

\section{Hasil dan Pembahasan}

Pengembangan media pembelajaran interaktif berbasis autoplay dilaksanakan dalam dua tahapan, dimana tahap pertama melakukan uji validasi terhadap media yang di uji oleh ahli media dan ahli materi. Untuk ahli media dari Media Pembelajaran di uji oleh Kepala Program Keahlian TAV di SMK N 3 Singaraja yaitu I Wayan Adi Perbawa, S.Pd., M.Pd.. Untuk uji materi di uji oleh guru mata pelajaran keterampilan yang mengajar di kelas X TAV yaitu Luh Dita Widyastuti, S.Pd. Untuk tahap kedua yaitu melakukan uji produk media di siswa kelas $\mathrm{X}$ TAV di SMK Negeri 3 Singaraja. Penelitian yang dilakukan adalah penelitian dan pengembangan media pembelajaran pada materi gerbang logika di kelas X TAV di SMK Negeri 3 Singaraja yang bertujuan untuk mengetahui kelayakan dan respon siswa terhadap media pembelajaran interaktif berbasis autoplay.

Penelitian ini merupakan penelitian yang dilakukan untuk mengetahui apakah Media Pembelajaran Interaktif Berbasis Autoplay sangat layak digunakan sebagai media pembantu dalam proses pembelajaran pada materi Gerbang Logika untuk siswa kelas X TAV di SMK Negeri 3 Singaraja serta mengetahui bagaimana respon siswa. Karena penelitian ini merupakan penelitian yang terbatas hanya mencari kelayakan dan respon maka produkyang dihasilkan tidak untuk di produksi masal.

Hasil penelitian menunjukan bahwa media pembelajaran interaktif berbasis autoplay layak digunakan sebagai media pembelajaran untuk siswa kelas X TAV pada materi Gerbang Logika di SMK Negeri 3 Singaraja. Dalam validasi desain yang menggunakan instrumen dengan skala Linkert untuk mendapatkan jawaban yang lebih nyata tentang pendapat atau sikap responden. Dari uji kelayakan media dalam aspek materi/isi, desain, kemanfaatan, bahasa, dan pengoperasian dalam materi Gerbang Logika. Untuk uji materi pada media pembelajaran yang di kembangkan peneliti di uji oleh guru materi pelajaran Gerbang Logika di SMK Negeri 3 Singaraja.

Hasil uji tingkat kelayakan dari media dan materi mendapatkan persentase masingmasing $90 \%$ untuk persentase ahli media, sedangkan untuk persentase kelayakan dari uji materi mendapatkan persentase $90 \%$. Maka hasil validasi dari media pembelajaran interaktif berbasis autoplay pada materi gerbang logika dinyatakan dalam kualifikasi sangat layak dan dapat di pergunakan untuk proses pembelajaran. Pada tahap uji coba produk, dengan menggunakan responden 5 siswa yaitu melakukan uji kelompok kecil mendapatkan hasil 87\% dan uji coba kelompok besar dimana hasil dari uji coba yaitu dengan persentase $91,37 \%$. Dengan kualifikasi sangat layak. 
Pada kelompok besar memperoleh hasil $91,37 \%$ dimana nilai tersebut masuk dalam kualifikasi sangat layak yang dapat dilihat pada Tabel 3.6. Sehingga media pembelajaran sudah dapat dimanfaatkan sebagai media pembelajaran dalam kegiatan belajar mengajar.

Table 2. Kriteria Poin

\begin{tabular}{lccc}
\hline Uji & Total Poin & $\%$ & Kriteria \\
\hline Uji Media & 81 & 90 & Sangat Layak \\
Uji Materi/lsi & 63 & 90 & Sangat Layak \\
Uji Kelompok Kecil & 262 & 87 & Sangat Layak \\
\hline
\end{tabular}

Dari hasil yang didapatkan selama penelitian membuktikan bahwa media pembelajaran interaktif berbasis autoplay pada materi gerbang logika lebih efektif digunakan selama pembelajaran di kelas.

Dari pembahasan diatas, jika dibandingkan dengan hasil penelitian lainnya yang serupa yaitu pada penelitian yang berjudul Pengembangan Media Pembelajaran Berbasis Multmedia Interaktif Autoplay Untuk Materi Pengenalan Komponen Elektronika Pada Siswa Kelas X TAV di SMK N 3 Singaraja yang dikembangkan oleh Ni Luh Paramita Dewi yang dimana hasil yang diperoleh dari ahli materi yaitu $96,15 \%$ lebih besar dari persentase yang diperoleh peneliti yaitu $90 \%$, kemudian hasil persentase yang diperoleh dari ahli media, penelitian yang dikembangkan oleh $\mathrm{Ni}$ Luh Paramita Dewi yaitu sebesar $93,31 \%$ lebih besar dari nilai persentase yang diperoleh peneliti yaitu $90 \%$. Kemudian pada penelitian Ni Luh Paramita Dewi tidak mencari respon siswa, sedangkan persentase yang diperoleh peneliti dari hasil uji coba kelompok besar mendapatkan91,37\%.

Meskipun memiliki perbedaan nilai dari perbandingan dari penelitian lain, baik lebih rendah maupun lebih tinggi, penelitian yang dikembangkan oleh peneliti sudah sesuai dengan hipotesis peneliti maka media pembelajaran yang dikembangkan peneliti dikatakan sangat layak untuk ahli materi dan ahli media dan sangat layak untuk respon siswa. Sehingga Pengembangan Media Pembelajaran Interaktif Berbasis Autoplay Pada Materi Gerbang Logika Untuk Siswa Kelas X TAV di SMK N 3 Singaraja layak digunakan sebagai media pembelajaran.

\section{Simpulan dan Saran}

Berdasarkan hasil dan pembahsan, dapat disimpulkan bahwa penelitian ini bertujuan untuk membuat media pembelajaran interaktif berbasis autoplay yang dapat digunakan untuk membantu proses pembelajaran, mengetahui tingkat kelayakan media pembelajaran dan respon siswa setelah menggunakan media pembelajaran interaktif berbasis autoplay. Hasil dari uji validasi desain media yang di uji oleh ahli media dan ahli materi dinyatakan sangat layak karena memiliki persentase yaitu $90 \%$, dalam kualifikasi sangat layak dan persentase ahli materi $90 \%$ dalam kualifikasi sangat layak. Untuk Uji coba kelompok kecil di peroleh hasil rerata persentase $87 \%$ dalam kualifikasi sangat layak, dan uji coba kelompok besar di peroleh hasil rerata presentase $91.37 \%$ dalam kualifikasi sangat layak.

Adapun saran yang di sampaikan yang berkaitan dengan penelitian pengembangan media pembelajaran interaktif berbasis autoplay pada materi gerbang logika yaitu sebagai berikut. Saran untuk siswa adalah agar menggunakan media pembelajaran interaktif berbasis autoplay pada materi gerbang logika sebagai media pendukung dalam pembelajaran.

Saran bagi guru adalah media pemebelajaran interaktif berbasis autoplay pada materi gerbang logika agar di terapkan lebih lanjut dalam proses pembelajaran di kelas sehingga dapat mencapai tujuan pembelajaran efektif dan efisien. 
Saran bagi kelapa sekolah adalah mengelola media pembelajaran interaktif berbasis autoplay ini dapat digunakan dengan baik, sebagai salah satu koleksi media pembelajaran yang dapat di manfaatkan oleh guru dan siswa.

Saran untuk peneliti lain adalah untuk pengembangan media pembelajaran interaktif berbasis autoplay pada materi gerbang logika belum sampai ke tahap pengukuran hasil belajar siswa. Oleh karena itu, perlu diadakan pengkajian lebih lanjut mengenai efektifitas penggunaan media pembelajaran interaktif berbasis autoplay yang berkaitan dengan pengukuran hasil belajar siswa menggunakan media pembelajaran interaktif berbasis autoplay melalui penelitian eksperimen dan memodifikasi media pembelajaran ineraktif berbasis autoplay agar tampilannya lebih menarik.

\section{Daftar Pustaka}

Alfin, Moch. 2015. Perbandingan Media Pembelajaran (Autoplay Media Studio) Sebagai Alat Bantu Pembelajaran Memperbaiki Cd Player Siswa Kelas Xi Di Smk Negeri 3 Surabaya. Arsa, I Putu Suka dan Agus Adiarta. 2017. Pengembangan Bahan Ajar Berbasis Multimedia Berorientasi Pemerdayaan Karakteristik Siswa Sekolah Menengah Pertama (SMP) di Jembrana. Denpasar: Seminar Nasional Vokasi dan Teknologi. 2542-2361. Arsyad, Azhar.2014. Media pembelajaran. Jakarta:PT Raja Grafindo Persada.

Dewi, NI Luh Paramitha. 2018. Pengembangan Media Pembelajaran Berbasis Multimedia Interaktif Autoplay Untuk Materi Pengenalan Komponen Elektronika Pada Siswa Kelas $X$ Tav Di Smk Negeri 3 Singaraja. Fakultas Teknik dan Kejuruan, Universitas Pendidikan Ganesha.

Hamalik, Oemar.2008. Perencanaan Pengajaran Berdasarkan Pendekatan Sistem. Jakarta: Bumi Aksara.

Herlambang, Made Dony. 2018. Pengembangan Simulasi pembangkit listrik energy terbaharukan sebagai media pembelajaran prakarya dan kewirausahaan kelas XI MIA SMA N 4 Singaraja

Hujair, Sanaki,Ah. 2013. Media Pembelajaran Interaktif-Inovatif. Yogyakarta: Kaukaba Dipantara

Musfiqon, 2012. Pengembangan Media dan Sumber Pembelajaran, Jakarta: PT Prestasi Pustakaraya

Narimawati, Umi. 2007. Riset Manajemen Sumber Daya Manusia. Jakarta: Agung Media.

Peraturan Pemerintah Nomor 32 tahun 2013 tentang standar nasional pendidikan.

Pratama, I Gede Eka Yoga. 2018. Pengembangan Media Pembelajaran Berbasis CD Interaktif pada mata pelajaran gambar teknik kelas X TITL di Smk Negeri 3 Singaraja. Skripsi (tidak diterbitkan).

Sugiyono, 2009. Metode Penelitian Kualitatif, Kuantitatif dan R\&D. Bandung: Alfabeta Sugiyono, 2015. Metode Penelitian Kualitatif, Kuantitatif dan R\&D. Bandung: Alfabeta Wandani, Nindy Mustika (2017). "Pengembangan Multimedia Interaktif Dengan Autoplay Media studio Pada Materi Kedudukan Relatif Dua Lingkaran." 
Jurnal Pendidikan Teknik Elektro Undiksha

Vol. 8 No. 1, April 2019

ISSN: 2599-1531

Yasa, Kadek Aditya Pradipta. 2017. Pengembangan Media pembelajaran Interaktif Berbasis Adobe Flash pada Mata Pelajaran Prakarya dan Kewirausahaan Materi Elektro(Listrik) untuk Siswa Kelas XI MIPA dan IPS di SMA Negeri 3 Singaraja. Fakultas Teknik dan Kejuruan, Universitas Pendidikan Ganesha. 